\title{
IS THE USE OF CARDIOACTIVE STEROIDS APPROPRIATE IN MANAGING ALUMINIUM PHOSPHIDE POISONING-INDUCED HEART FAILURE?
}

\author{
Sayed Mahdi MARASHI ${ }^{1}$, Mohammad MAJIDI ${ }^{2}$, Mehran SADEGHIAN ${ }^{3}$, Shapour AHMADI ${ }^{4}$, \\ Hojatollah RAJI ASADABADI ${ }^{5}$, and Zeynab NASRI NASRABADI ${ }^{6}$ \\ Legal Medicine Research Center, Legal Medicine Organization, Tehran ${ }^{l}$, Ayatollah Taleghani Hospital, Urmia \\ University of Medical Sciences, Urmia ${ }^{2}$, Department of Forensic Medicine and Clinical Toxicology ${ }^{3}$, Department of \\ Internal Medicine, Shariati Hospital ${ }^{4}$, Children Medical Center ${ }^{6}$, Tehran University of Medical Sciences, Tehran, \\ Department of General Surgery, Alzahra Hospital, Isfahan University of Medical Sciences, Isfahan ${ }^{5}$, Iran
}

Following the publication of a review on aluminium phosphide poisoning in your journal, as well as another letter to the editor regarding this subject, we would like to add to this discussion $(1,2)$. Patients with acute aluminium phosphide poisoning generally suffer from multiple organ dysfunction due to diminished mitochondrial activity and oxidative phosphorylation. This is the result of the direct effect of toxins on mitochondrial performance $(3,4)$.

As Shadnia et al. (5) stated, this toxicity may, among other consequences, lead to congestive heart failure. Cardioactive steroids were until recently considered as a supposition that improves cardiac functioning and were used in the treatment of heart failure (6).

In fact, in the acute phase of poisoning, the clinical presentations include: hypovolemia, shock, tissue hypoxia, decreased oxygen consumption, and decreased cardiac output, as well as accumulation of serous fluid in body cavities and congestion of vital organs. Even though these symptoms resemble manifestations of heart failure, Marashi et al. (7) believe that the real reasons behind these symptoms are the transfer of intravascular fluid into the third space and the consequent hypovolemic shock that results from the breach of vascular wall integrity, therefore causing metabolic acidosis.
Similarly, other studies (8) have shown that, despite the high central venous pressure and hypokinesia of the left ventricle, volume resuscitation with excessive amounts of fluid in patients with acute aluminium phosphide poisoning cannot be associated with severe problems such as pulmonary oedema (9).

Thus, in contrast to Shadnia et al. (5), we believe that the "heart failure" associated with this toxicity is not true heart failure. In addition to the break redox activity of myocardiocyte mitochondria in the context of diminished phosphine-induced oxidative stress (3, 4), Shapiro (10) asserted that metabolic acidosis could also cause decreases to cardiac function via intracellular acidosis. Moreover, some scientists believe that the inhibition of metabolism and necrosis of the myocardiocytes may lead to the generation of reactive oxygen radicals (11). It is clear that in such conditions, the polarization of myocardiocytes is not conceivable. Thus, the inhibition of $\mathrm{Na}^{+} / \mathrm{K}^{+}$-ATPase by a cardioactive steroid does not have an important role in improving cardiac function.

Other studies (12) have indicated that cardioactive agents should not be used in the management of acutely decompensated heart failure patients. Although the use of cardioactive steroids is associated with 
reducing hospitalization time in cases of heart failure, it does not have a role in reducing mortality (13).

Finally, we should keep in mind that hypomagnesaemia, another important result of aluminium phosphide poisoning, can be amplified by cardioactive steroid-induced magnesuria making the patient vulnerable to refractory arrhythmias $(8,14)$.

\section{REFERENCES}

1. Mehrpour O, Jafarzadeh M, Abdollahi M. A systematic review of aluminium phosphide poisoning. Arh Hig Rada Toksikol 2012;63:61-73.

2. Nasri Nasrabadi Z, Marashi SM. Comments on "A systematic review of aluminium phosphide poisoning". Arh Hig Rada Toksikol 2012;63:551, doi: 10.2478/10004-1254-63-20122321

3. Chefurka W, Kashi KP, Bond EJ. The effect of phosphine on electron transport in mitochondria. Pest Biochem Physiol 1976;6:65-84. doi: 10.1016/0048-3575(76)90010-9

4. Grander W, Dünser MW. Prolonged inflammation following critical illness may impair long-term survival: a hypothesis with potential therapeutic implications. Med Hypotheses 2010;75:32-4. doi: 10.1016/j.mehy.2010.01.020

5. Shadnia S, Sasanian G, Allami P, Hosseini A, Ranjbar A, Amini-Shirazi N, Abdollahi M. A retrospective 7-years study of aluminum phosphide poisoning in Tehran: opportunities for prevention. Hum Exp Toxicol 2009;28:209-13. doi: 10.1177/0960327108097194

6. Mehrpour O, Farzaneh E, Abdollahi M. Successful treatment of aluminum phosphide poisoning with digoxin: a case report and review of literature. Int J Pharmacol 2011;7:761-4. doi: 10.3923/ijp.2011.761.764

7. Marashi SM, Arefi M, Behnoush B, Nasrabad MG, NasriNasrabadi Z. Could hydroxyethyl starch be a therapeutic option in management of acute aluminum phosphide toxicity? Med Hypotheses 2011;76:596-8. doi: 10.1016/j. mehy.2011.01.009

8. Chacko J, Shivaprasad C. Fatal aluminium phosphide poisoning due to myocardial depression refractory to high dose inotropic support and intra-aortic balloon counterpulsation. Indian J Crit Care Med 2008;12:37-8. doi: 10.4103/0972-5229.40949

9. Singh S. Aluminum phosphide poisoning [displayed 22 August 2013]. Available at http://www.asiatox.org/ 6th\%20APAMT\%20pdf/Aluminum\%20Phosphide $\% 20 \mathrm{P}$ oisoning.pdf

10. Shapiro JI. Pathogenesis of cardiac dysfunction during metabolic acidosis: therapeutic implications. Kidney Int 1997;61(Suppl):S47-51.

11. Lall SB, Sinha K, Mittra S, Seth SD. An experimental study on cardiotoxicity of aluminium phosphide. Indian J Exp Biol 1997;35:1060-4. PMID: 9475040

12. Allen LA, O'Connor CM. Management of acute decompensated heart failure. CMAJ 2007;176:797-805. doi: 10.1503/cmaj.051620

13. Kenny T. The Nuts and Bolts of Cardiac Resynchronization Therapy. Massachusetts: Blackwell Publishing; 2007.

14. Moe SM. Disorders involving calcium, phosphorus and magnesium. Prim Care 2008;35:215-37. doi: 10.1016/j. pop.2008.01.007

\section{CORRESPONDING AUTHOR:}

Zeynab Nasri Nasrabadi

Tehran University of Medical Sciences,

Children Medical Center

No 62, Dr Gharib St, Tehran, Iran

E-mail: nasri_z@razi.tums.ac.ir 